\title{
UN HIMNO NO CONVENCIONAL EN MEDEA DE EURÍPIDES ${ }^{1}$
}

\author{
ANA MARÍA GONZÁLEZ DE TOBIA \\ Centro de Estudios Helénicos \\ Universidad Nacional de La Plata
}

A Filomena Hirata, con profundo afecto, respeto y admiración, en una nueva coincidencia de nuestro encuentro con Eurípides

\begin{abstract}
Resumen: La integración estética del coro en la tragedia griega resulta una tarea crítica atractiva. En varias oportunidades hemos expuesto nuestra posición respecto de la funcionalidad coral dentro de la producción trágica de Eurípides. El tercer estásimo de Medea nos proporciona un corpus adecuado para demostrar que la representación ficcional de la actividad teatral, sosteniendo la mimesis cultual original, provee la poíesis mitohistórica en honor de la Atenas contemporánea a Eurípides.
\end{abstract}

Palabras clave: Coro, estásimo, Eurípides, Medea, Poíesis mitohistórica

Diferentes estudios han demostrado continuidad entre las formas corales del período arcaico y las representadas sobre el escenario trágico de la Atenas clásica. Ambas formas muestran ritmos, peculiaridades dialécticas, usos léxicos y, en ciertas ocasiones, fórmulas rituales comparables. ${ }^{2}$

Los griegos mismos observaron la representación trágica como derivada de las representaciones corales. Heródoto muestra a Clístenes de Sicyon transfiriendo

1 Este artículo, con modificaciones, fue presentado en el XVII Simposio Nacional de Estudios Clásicos. Bahía Blanca, septiembre de 2002.

2 Entre los trabajos aludidos, cfr. T. B. Wester, The Greek Chorus, London, Methuen, 1970, 110-32); H. Parry, The Lyric Poems of Greek Tragedy, Toronto and Sarasota, Samuel Stevens, 1978, passim) y el insoslayable trabajo pionero de W. Kranz, Stasimon, Berlín, Weidmannsche Buchhandlung, 1933, en especial 127-48. Más tarde, los artículos publicados en Arion 3.1, 1994-1995 plantearon interesantes propuestas sobre el tema. Se destacan los artículos de G. Nagy, 41-55, A. Henrichs, 56-11 y C. Calame, 16-154. 
los "coros trágicos" desde la celebración de Adrasto al culto de Dionisio. Aristóteles señaló el origen de la tragedia en el ditirambo, una forma coral dedicada al mismo dios y Diógenes Laercio afirma que Solón atribuyó la primera representación dramática de una "tragedia" a Arión, el compositor de ditirambos, aquellas primeras representaciones dramáticas representadas sólo por coros. ${ }^{3}$

A pesar de estas y otras afinidades, las transformaciones substanciales también marcan el pasaje de la expresión coral, con su valor ritual y performativo, a la orchestra del teatro de Atenas. ${ }^{4}$ En esta transformación, las palabras actuales del grupo coral no perdieron completamente la función cultual. En términos espaciales, es como si se hubiera registrado una simple transferencia de un santuario que tradicionalmente sirvió como sitio del canto coral, a otro santuario que fue dedicado a Dionisio Eleutheros y sirvió como sitio a un festival particular. Ambas clases de performance demandaron la participación de la comunidad. ${ }^{5}$ En los coros trágicos, los coreutas no sólo apelan a los dioses, en una acción cultual, representando a los miembros de la comunidad, sino que también actúan como actores representando escenas de una acción heroica, sobre el escenario. Desde ese punto de vista, los coros trágicos cambian su función: se involucran en una acción cultual para Dionisio y representan al espectador sólo indirectamente.

Los efectos de la trasferencia de la forma poética del período arcaico al escenario trágico no están limitados simplemente a cambios rítmicos, dialectales o léxicos. Necesitamos agregar las descripciones de la acción, que es el punto en el que los cantos corales mélicos y trágicos difieren. El canto cantado por el coro sigue siendo una acción y como acción preserva su función ritual y cultual, pero sus modalidades sufren importantes modificaciones. El coro tiene una doble función: representa la voz del intermediario entre la polis y la entidad o dios invocados y, a su vez, como "voz narrativa" representa el papel de intermediario entre lo que los

3 Heródoto, Historia, 5.67.5; Aristóteles, Poética, 1449a 11; Solón, fr. 39; Diógenes Laercio, Vida de Solón, 3.56.

4 Convenimos con C. Calame, From Choral Poetry to Tragic Stasimon, Arion,3 1, 1994. 95, 149, en la necesidad de aclarar el sentido generalizado del término "performativo", entendiéndolo como marca Austin (How to do Things with Words, 1975, 6-7) citado por Calame: "[performative] indicates that the issuing of the utterance is the performing of an action -it is not normally thought of as just saying something".

5 Cfr. S. Goldhill. "The Great Dionysia and Civic Ideology” Winkler, J. and Zeitlin, F. (eds) Nothing to do with Dionysos?, Athenian Drama in its Social Context. Princeton, Princeton University Press, 97-129 entre otros. 
espectadores ven y lo que no ven. ${ }^{6}$ Acompañando estas dos voces del coro, ritual y narrativa, hay una tercera voz, que expresa emoción, especialmente en coros que representan a mujeres jóvenes. ${ }^{7}$

La disociación entre las variadas funciones asignadas a la voz performativa y autorreferencial del coro trágico es, probablemente, el resultado de los efectos de distanciamiento aportados por la dramatización de un argumento mitológico legendario y su realización en un festival dedicado a Dionisio: la distancia entre la Atenas del espectador y los lugares representados sobre el escenario; la distancia entre las palabras expresadas por los actores y su autor; la distancia creada por el uso de vestuario y máscara y la distancia provocada por el hecho de que los roles femeninos fueran actuados por actores del sexo opuesto, revirtiendo las categorías de género.

Por su capacidad de expresar emociones fuertes, el coro aparece como el más poderoso vehículo para impulsar a los espectadores a la piedad y el temor, que son las funciones que Aristóteles le atribuyó al coro trágico, vale decir su colaboración con la acción dramática como sunagonízethai. Más aun, la indeterminada primera persona del coro "habla" para que los espectadores rindan honor a Dionisio Eleutheros, como en la performance pública de los poemas líricos arcaicos, que estrechaba a espectador y coro en un acto ritual. Por el hecho de que se delegue en el coro la función que pertenece a la performance ritual de la tragedia ática, la que impulsa al espectador a la piedad y el temor, la comunidad cívica retorna a la normalidad y al equilibrio. Esta puede ser la clave para el misterio de la catarsis aristotélica. Sin embargo, el coro tiene una nueva función más allá de la voz ritual y emocional de los coreutas, una función que es, a través de la descripción y la narración, explicativa y, hasta cierto punto, hermenéutica. Esto puede corresponder a la función primaria atribuida a la tragedia clásica por sus contemporáneos: educar a los ciudadanos por significados de emociones elevadas por la representación poética. ${ }^{8}$

6 C. Calame, Choruses of Young Women in Ancient Greece, Lanham Boulder, New York, London, Rowman \& Littlefield, 1997, passim) considera la voz del coro trágico como "voz narrativa" y esta denominación ha sido adoptada por la mayor parte de la crítica especializada.

7 C. Calame, op. cit.,1994-95, 136-154 establece la triple función del coro y la ejemplifica con el análisis de Píndaro, fr. 94b; Esquilo, Siete contra Tebas 78-180 y Eurípides, Fenicias 207-260.

8 Aristófanes, Ranas 1009-10 y 1919. 
El primer libro del primer poema, Ilíada, sentó un paradigma que resultó una validación virtualmente universal para los siguientes ocho siglos. A partir de Ilíada I.472-74, se observan como paradigmáticos los siguientes elementos: 1) la identificación de un agente divino personal, como causa de un problema humano y 2) la tentativa de remediarlos con ritos confeccionados para construir la identidad del agente divino. ${ }^{9}$ La religión griega frecuentemente se revela a sí misma como medicina para el individuo o la sociedad, ofreciendo el lenguaje simbólico de diagnóstico y curación.

En época de Eurípides, Atenas estuvo protegida por una armada experta y también por dioses que, mediante rituales, fueron hechos responsables de la mayor o menor efectividad en el cuidado de la ciudad. Los oráculos, interpretaciones de sueños, cultos iniciáticos, etc. fueron fuentes de experiencia divina que ofrecieron respuestas individuales o estatales. Los individuos ofrecían plegarias y sacrificios a determinada deidad. La distinción entre himno de culto y plegaria involucra, fundamentalmente, una cuestión de énfasis y, en el caso de Píndaro, los himnos tienden, en su curso, a mover de lo general a lo específico: primero es invocado el dios, luego es definida su identidad con precisión, mediante epítetos seleccionados y epikleseis; se enumeran sus poderes y realizaciones, utilizando varias formas de predicación, todas ellas vinculantes con la formulación de un pedido preciso al final. La función de la invocación es preparar para el pedido, por la definición de aquellos poderes que quien entona el himno desea explorar. ${ }^{10}$

La tragedia de Eurípides contiene numerosas aproximaciones a himnos de culto, fundamentalmente a dioses olímpicos, como el de Atenea Nike y a Apolo, en Ión 452-471 y 881-922, respectivamente; a Atenea y otras divinidades, en Heraclidas 748-783; a Artemisa, en Hipólito 58-71, a Apolo y Artemisa en Ifigenia en Táuride 1234-1282, a Ares en Fenicias 74-800, a Artemisa en Ifigenia en Áulides 1521-1531, el himno a los Dioscuros, que cierra el tercer estásimo de Helena. Pero la tragedia incluye conflictos más abstractos y más intelectuales o ideológicos, por eso encontramos en Eurípides una extensión de rango de conceptos y entidades

9 Se trata del pasaje en el que la armada Aquea, acosada por la plaga a la que ellos no encuentran remedio, envían una misión al sacerdote de Apolo, Crises, quien anuncia que Apolo está ofendido por el tratamiento que Agamenón dio a la hija del sacerdote. El dios envió la plaga como castigo. La reparación consiste en devolver a Criseida y apaciguar a Apolo con ritos: sacrificio, purificación y, sobre todo, el canto de peanes al dios.

10 Cfr. Race, Style and Rhetoric in Pindar' Odes, American Philological Association, American Classical Studies no.24. Atlanta, Scholars Press, 1990, 91. 
que están invocadas en sus himnos. En Alcestes, por ejemplo, encontramos un himno que invoca la casa de Admeto (569-605) como un encomio a la hospitalidad y a Anagke (962-983). La tendencia de Eurípides a elevar las abstracciones al status de divinidades fue parodiada por Aristófanes, en Ranas 889 y siguientes; sin embargo, podemos citar ejemplos serios y de gran valor dramático como el himno a Hosia, en Bacantes 370 y ss., el himno a Hypnos en Orestes 174-186, el himno a Hymenaios en Troyanas 308-341, los himnos a Eros y Afrodita en Hipólito 525-563 y $1268-1281$ y el himno a Atenas, en Medea 824-865, entre otros. ${ }^{11}$

Los coreutas de las tragedias de Eurípides contaron con la certeza de que la representación coral de cierto tipo de himnos lograba un efecto teatral considerable. Para su audiencia, eran familiares las circunstancias bajo las cuales los varios tipos de himnos eran cantados convencionalmente en la vida real: el peán como plegaria por una victoria; el himeneo para celebrar una boda; un parteneion cuando las jóvenes celebraban su salida a la existencia de una posible experiencia matrimonial, etc. En cada ocasión, Eurípides extrae algún elemento del canon de cantos líricos tradicionales para delinear un punto dramático o mostrar como un personaje teatral está en oposición a la norma social. Eurípides ejecuta, por yuxtaposición los cantos tradicionales con sus asociaciones convencionales y la acción escénica. De esta manera, los cantos corales sientan una norma en contraste con la que los individuos agonizan en la obra. La sociedad tiene sus hábitos y sus convenciones que resultan predecibles e iterativas, mientras que la vida individual está marcada por giros que impiden complicidad con estas normas.

Eurípides utiliza pasajes de la lírica coral, elaborados en varios tipos de himnos de culto: 1) para "diagnosticar" las relaciones problemáticas de uno o más caracteres con los miembros de la comunidad olímpica, representando realidades sociales y psicológicas en sus palabras. 2) para fortalecer el drama en los puntos clave por mostrar miembros de la comunidad dramática comprometidos en actividades de plegaria o himno que en la vida real fue intentado para alejar la crisis o celebrar la realización, mediante la invocación al pensamiento de los dioses como responsables de ayuda o clemencia y 3) para utilizar los paradigmas de la poesía de culto en toda su variedad, de modo de crear una atmósfera ritual en el drama. Eurípides repetidamente conduce fuera la expectativa elevada por un cierto tipo

11 Cfr. W. Furley "Hymns in Euripidean Tragedy", en Cropp. M., Lee, K y D. Sansone, Euripides and Tragic Theatre in the Late Fifth Century, Illinois Classical Studies 24-25 1999. 2000, Illinois, Stipes Publishing L. L. C., Champaign 2000, para un recuento más exhaustivo de ejemplos. 
de canto de culto contra la situación dramática que él mismo creó. Esta es una forma de ironía.

Los esquemas tradicionales de himnos son aquellos que presentan un proemio al dios, con apóstrofe, indicación de que el poeta comienza su canto celebrándolo; un "centro" mítico relativo al mismo y un epílogo de bendiciones o plegarias. En la lírica de los coros trágicos se producen las denominadas "desviaciones de la hímnica”, motivadas por la sustitución del dios por personificaciones o personas que lo reemplazan. Se puede tratar de productos literarios en virtud de las cuales el poeta se centra más en temas que personalmente le interesan, porque forman parte de su sentir. ${ }^{12}$

Los Alejandrinos utilizaron la palabra humnos para describir un género poético, sin saber exactamente a qué forma específica correspondió la denominación con un contenido específico. El himno se define a sí mismo como un canto en el cual dioses y héroe son celebrados. La variedad semántica de cantos contenida en el término humnos es destacable, no sólo por su contenido, sino por su ejecución. Los himnos pudieron tener canto y danza, sin movimiento del coro y esto también pudo haber sido transferido a los coros trágicos. El significado general del término no indica un género lírico definido al cual cierta categoría de cantos cantados por coros femeninos pudieran pertenecer. Esto lo diferencia de otros géneros líricos.

Dentro de este marco, analizaremos la función del estásimo tercero de Medea como un himno no convencional, que abastece una comprensión formal e interpretativa de la obra, mediante una poíesis mitohistórica. ${ }^{13}$

El tercer estásimo de Medea (824-865) con su espléndido encomio de las excelencias culturales y de la belleza natural de Atenas, es uno de los pasajes más celebrados de la poesía de Eurípides. La estructura general del estásimo es simple y clara: el primer par de estrofas elogia a la ciudad, comenzando en la primera estrofa, en términos generales con su divina protección (824-26) antes de dirigirse a especificar en particular su sabiduría y cultura (Armonía y las Musas, 829-34) y luego, en la primera antiestrofa, continuando con un aspecto particular, está incluida Afrodita (835-40) para concluir con la combinación climática de ambos

12 F. Rodríguez Adrados, Orígenes de la lírica griega, Madrid, Revista de Occidente, 1976, 231-234.

13 Cfr. Nuestro artículo A. M. González de Tobia, A. M. "Doble logos en Medea", Argos, Revista de la Asociación Argentina de Estudios Clásicos, año VII, N 7, (Buenos Aires, 1983, pp 101 - 112) donde analizamos en su totalidad el itinerario del coro en Medea de Eurípides. 
temas por la correlación entre Sofía y Erotes (840-45). El segundo par de estrofas diseña las consecuencias, a partir de la caracterización de Atenas, y las aplica a la situación dramática específica, dirigiéndose a Medea directamente, preguntándole cómo una ciudad sagrada podría aceptarla si ella matara a sus hijos (846-50); rogándole que desista de su horrendo plan (851-55); asombrándose de cómo podría tener ella la suficiente audacia como para llevarlo a cabo (856-62) y sugiriendo, finalmente, que, seguramente, Medea sería incapaz de realizarlo (863-65).

Desde el punto de vista formal, el estásimo está compuesto por dos pares estróficos; presenta la forma de un himno y su destinataria primaria es Atenas.

A los fines de nuestro análisis, utilizaremos la edición de D. Kovacks, de $1994 . .^{14}$

Desde el punto de vista compositivo, el primer par estrófico presenta un equilibrio formal destacable $\mathrm{e}^{15}$ y está constituido por estrofa y antiestrofa en metro dáctilo epitrito. ${ }^{16}$

Estrofa A

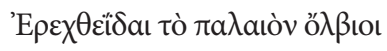

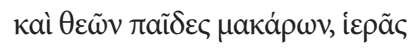

825

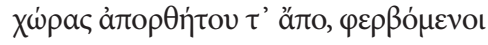

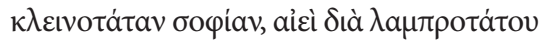

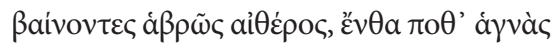

830

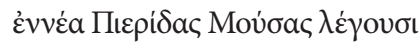

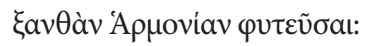

Antiestrofa A

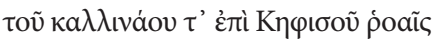

835

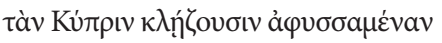

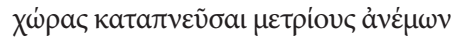

14 D. Kovacs, Euripides, Volume I, Cyclops, Alcestis, Medea, Loeb Classical Library, Cambridge, Massachusetts,London, Harvard University Press,1994.

Cfr. D. Page, Euripides Medea, Oxford, Oxford University Press, 1964.

16 El dáctilo epitrito, en la poesía dramática, ofrece la más cercana aproximación al estilo periódico de composición y algunas veces difícilmente distinguible de las más regulares stanzas pindáricas, en cuanto a su técnica. El efecto es aproximar estas stanzas para que prevalezca la manera de composición dramática por cola. Cfr. Dale, The Collected Papers, Cambridge, Cambridge University Press,1969, 59. 


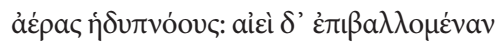

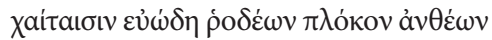

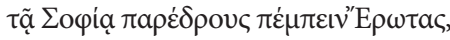

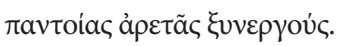

Son prósperos desde antaño los descendientes de Erecteo, hijos de los dioses bienaventurados, nacidos en una región sagrada inexpugnable, porque se alimentan con la sabiduría más ilustre, al marchar siempre, pomposamente, a través del más brillante éter, allí donde se dice que, alguna vez, las sagradas Musas de Pieria engendraron a la rubia Armonía.

Se celebra que Cipris, que alguna vez extrajo agua de las corrientes del Cefiso, hace correr bellas ondas, para enviar soplos moderados de los vientos; y siempre, mientras se arroja sobre los cabellos una corona perfumada trenzada con rosas, envía a los Amores, compañeros de la Sabiduría y generadores de toda clase de virtudes.

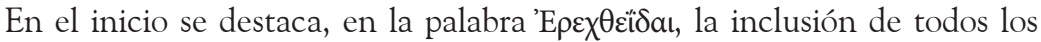
atenienses, desde la fundación mitohistórica de la ciudad, atribuyéndoles dos cua-

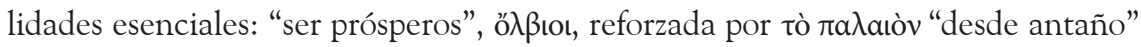

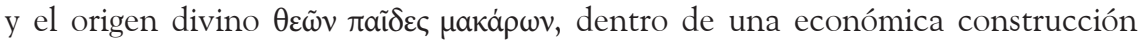
nominal. A partir de la ubicación anticipada de una circunstancia, que destaca la cualidad de i̊pã $\chi \omega ́ p a \varsigma$, a modo de nacimiento de una región, se encadenan dos acciones secundarias que sostienen el núcleo original. Se trata de destacar

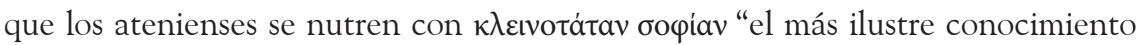
general, en especial artes y ciencias"17 y, además, "marchan siempre a través del

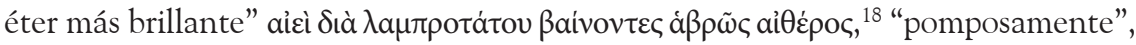

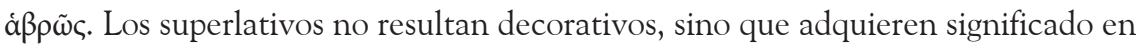

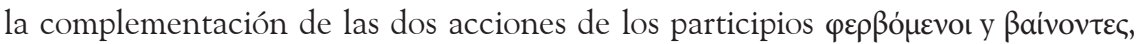
que implican la salud del espíritu y del cuerpo. La quiebra producida por una proposición de relativo, que introduce el adverbio ěv $\theta a$, actúa como gozne eficaz para vincular no sólo la acción impersonal que cierra la estrofa ( $\lambda \dot{\gamma} \gamma o v \sigma \mathrm{l})$, sino también

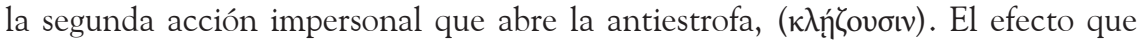
produce la proposición de relativo es el de la amplificación del espacio, mediante los verbos argumentativos: el primero introduce a las nueve Musas de la Pieria y a

17 Cfr parodia, en Aristófanes, Nubes, 1204.

18 Tema que interesó, fundamentalmente a los filósofos jónicos. 
Armonía, como la unión de las nueve Musas. Todas ellas constituyeron su hogar en Atenas. El segundo verbo introduce a Cipris como causante del buen clima de la región caracterizada por la mención del Cefiso, que actualiza, a modo de eco y paralelo, la ancestral estirpe ateniense, aludida en Erecteo, al comienzo. La acción de Cipris se continúa como dadora de amores adláteres de la sabiduría y consejeros de toda clase de excelencia.

El encadenamiento mitohistórico resulta actualizado y vigente, por medio de

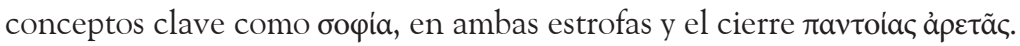

La narración lírica del primer par estrófico conforma una aretalogía de Atenas, que nos permite considerar a la ciudad como abstracción u objeto de celebración, dentro de las características formales del estilo hímnico, ya sea que la consideremos un encomio o bien una asimilación a ciertos rasgos del epinicio que asimila el vencedor a su ámbito, vale decir a su ciudad, y la gloria le pertenece a ambos.

En el segundo par estrófico prevalece el verso prosodíaco.

Estrofa B

$$
\begin{aligned}
& \pi \tilde{\omega} \varsigma \text { oũv i } \varepsilon \rho \tilde{\omega} \nu \pi 0 \tau \alpha \mu \tilde{\omega} v
\end{aligned}
$$

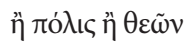

$$
\begin{aligned}
& \pi \dot{\mu} \mu \pi \iota \dot{\rho} \varsigma \text { } \sigma \varepsilon \chi \omega \dot{\omega} \rho \alpha
\end{aligned}
$$

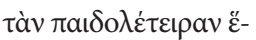

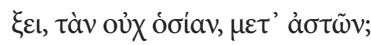

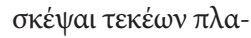

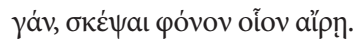

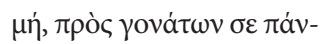

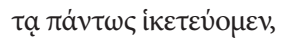

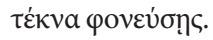$$
850
$$

Antiestrofa B

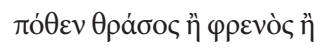

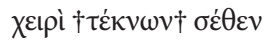

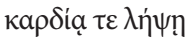

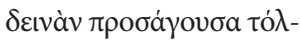

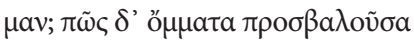

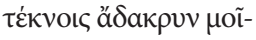




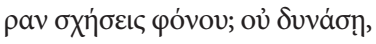

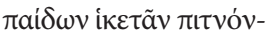

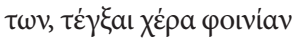

$\tau \lambda a ́ \mu o v ı ~ \theta v \mu \tilde{\omega}$.

¿Cómo, entonces, la ciudad de ríos sagrados o la región hospitalaria de los dioses, te recibirá a ti, la filicida, la que no es pía, en medio de sus ciudadanos? Considera el golpe contra tus hijos, considera qué crimen vas a cometer. De rodillas, absolutamente todos te suplicamos iNo mates a tus hijos!

De dónde obtendrás la osadía tanto para tu mente como para tu mano y tu corazón, si llevas a cabo el terrible acto audaz contra tus hijos? ¿Cómo, después de lanzar una mirada a tus hijos, vas a dejar desprovisto de lágrimas su destino de muerte? No podrás teñir de sangre tu mano con ánimo inconmovible, cuando tus hijos caigan (a tus pies) como suplicantes.

El segundo par estrófico inicia una esfera volitiva, mediante una interrogación directa, especificada en $\sigma \varepsilon$ (Medea) y que actúa como colofón del primer

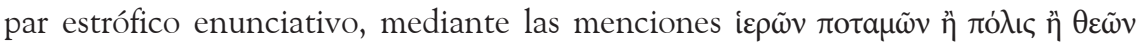

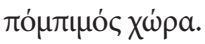

Las expresiones imperativas y prohibitivas que siguen expresan el motivo específico del asesinato de los hijos y luego aparece el yo coral con el verbo de

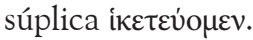

El cierre de la antiestrofa resulta una falsa prospección de los acontecimien-

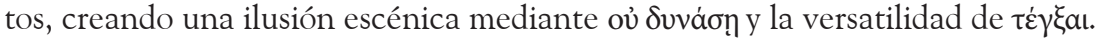

Dentro del espacio teatral de Corinto, donde se desarrolla la acción de la tragedia, aparece otro espacio, por obra del coro; es Atenas. La triplicación de espacios beneficia a Atenas y otorga pertenencias. Medea proviene de los márgenes de la tierra, la Cólquide y allí define su pertenencia. La situación trágica tiene como lugar Corinto, espacio que, en realidad, desde el punto de vista trágico, sólo sirve como contraste, ya que la acción que en él se desarrolla, surge de la presentación de la lejana Cólquide y de la vigencia ética impuesta resolutivamente por Atenas.

Las características que el coro le otorga a Atenas y a los atenienses, en la estrofa, se expande en dotes de sabiduría ilustre, excelencia en su aire y jerarquía artística por el alumbramiento de las nueve Musas.

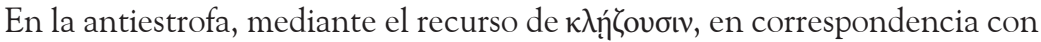
$\lambda \varepsilon \dot{y}$ ovoı anterior, se exaltan las bondades climáticas del lugar, fácilmente ubicable 
por la alusión al río Cefiso. Las referencias míticas fundacionales se inmediatizan

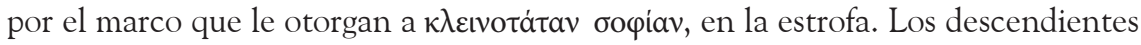
de Erecteo, vinculados a los dioses bienaventurados, y por otra parte Armonía y sus descendientes la Musas, encierran la sabiduría ilustre de los habitantes del lugar. ${ }^{19}$ Se unifica la referencia ritual.

En la antiestrofa, el espacio adquiere una dimensión de lugar físico, complementario del espacio mítico, ritual e intelectual anterior. Cipris ofrece la alusión mitológica precisa, para acompañar la anticipada locación que expresa las ondas del Cefiso. La referencia a Lopía personificada, actúa como cierre del circuito

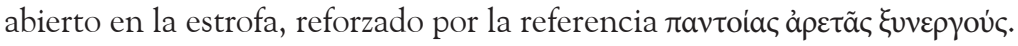

En la segunda estrofa, cambia el estilo y de la narración lírica anterior se

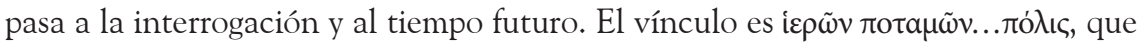
actúa como eco y paralelo con ípã $\chi \omega \dot{\omega} \rho a \varsigma$, de la primera estrofa y se refuerza en

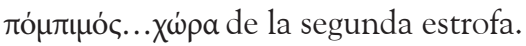

La aretalogía deja lugar a la imprecación y aparecen los imperativos y prohibitivos pronunciados por el coro que, sin embargo, tiene una interlocutora inconfundible. Surge la segunda persona singular como reafirmación de la primera

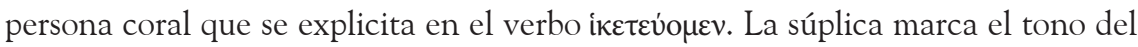
himno. Hay un objeto de suplica y un destinatario que, por la posibilidad de condena de sus acciones, reafirma la piedad exigida por Atenas.

La segunda antiestrofa está construida como paralelo, con una primera interrogación, y reemplaza las expresiones volitivas con la utilización enunciativa de

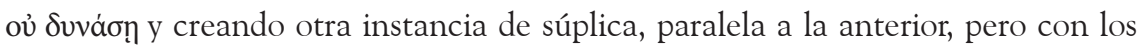
hijos de Medea como objeto, en una construcción subordinada, continuando la tónica de censura exhibida en la estrofa.

En la economía dramática del estásimo, los tiempos actúan como pasados rotundos, cuando se hace referencia al mito fundacional. El presente se actualiza

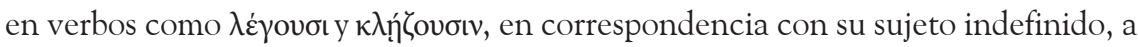
modo de presente extendido en la sanción comunitaria. En el último par de estrofas predomina el futuro, a modo de vinculación con la resolución trágica.

El espacio escénico deja lugar, por un breve lapso, al otro espacio, que si bien actuará como posibilidad de refugio futuro y como motor que posibilita la acción, se diseña a partir del canto coral, cantado por mujeres Corintias, que, en

19 Cfr. esta alusión en Aristófanes, Nubes 1204. 
realidad, son jóvenes Atenienses que pertenecen a la audiencia y la comunidad que presencia la representación.

El tiempo vivido colectivamente, deviene, gracias a este intermediario, en tiempo colocado en discurso y narrado; deviene el tiempo historiográfico que no sólo es un tiempo simbólico e historicopoiético, sino que es también un tiempo en grado de devenir intermedio, con sus efectos ideológicos.

Constituido como representación del pasado, este tiempo puede devenir activo en la comunidad que distribuye la creencia en ese pasado y de la cual el pasado ha estado reconstruido, mediante los poetas.

Gracias a esta metamorfosis, la distinción dada entre tiempo del mito y tiempo de la historia deja de ser pertinente.

El tiempo crónico se constituye en su linealidad a partir del "tiempo mítico" con el uso del aspecto cíclico. No obstante ha sido llamado a regular el tiempo de la comunidad política y cultural, es decir el cómputo del tiempo calendario.

Los mitos pueden haber llegado a nosotros a través del arte y de la literatura, pero se desarrollaron en performances sociales más generales y funcionan como una especie de sistema comunicacional, una manera de producir afirmaciones significativas dentro de un grupo que conoce las historias.

Si consideramos la simetría axial que presenta la tragedia, la presencia de Atenas en Medea constituye el delicado equilibrio entre lo perfecto y lo imperfecto, que constituye la alternancia imprescindible para lograr la proporción regular en las expresiones del arte griego. ${ }^{20}$

El estásimo tercero, constituido por un himno a Atenas, se ubica en un centro estructural, que está encerrado por un primer amillo compositivo compuesto por el segundo episodio y el segundo estásimo, por una parte, y el cuarto episodio y el cuarto estásimo. Atenas como espacio de salvación está presente con igual intensidad en los planes de muerte de la escena con Egeo y en la salvación que manifiesta el coro del cuarto estásimo. Con una amplificación mayor, el tercer estásimo es centro de un segundo anillo compositivo, que abarca el primer episodio y el primer estásimo, por una parte, y el quinto episodio, por otra. La Medea extranjera del primer episodio, está diseñada en función del diseño de Grecia del primer está-

20 Cfr. A. Esteban Santos "Composición axial en Eurípides en torno a la mujer y la muerte" en García Novo, E y Rodríguez Alfageme, I. (eds.) Dramaturgia y puesta en escena en el teatro griego, Madrid, Ediciones Clásicas, 1998, 102-103. 
simo. Medea extranjera del quinto episodio ya está diseñada en función de la extrañeza de su conducta frente a la ética griega. Por último, un tercer anillo presenta prólogo y paródos como apertura y quinto estásimo y éxodo, en el cierre. Eurípides representa una relación incierta entre identidad y espacio, porque crea una Atenas representada en la tragedia, que constituye en sí misma otra escena. Medea tiene un status marginal en Corinto y en su mundo inmediato no hay centro. Al final de la obra, Medea aparece sobre su carro en lo alto del palacio y demuestra que tiene un único espacio para ir: arriba, el de los cielos, fuera del ámbito de los discursos, lo cual, en una espléndida ironía de Eurípides, también marca el ingreso del Medea en el mito y el discurso de Atenas, una Atenas, que, en realidad, no da asilo a Medea dentro de los límites de la obra, pero ha sido el eje espacial de la ficción. ${ }^{21}$

BibLIOGRAFÍA

\section{Edición utilizada:}

Page, D. (ed.) Euripides Medea, Oxford.

\section{Crítica citada:}

Austin, J. L. (1975) How to Do Things with Words, Cambridge.

Calame, C. (1994-1995) "From Choral Poetry to Tragic Stasimon", Arion 3.1: $136-154$.

(1997) Choruses of Young Women in Ancient Greece, Lanham, Boulder, New York, London.

Croally, N. T. (1994) Euripidean Polemic, Cambridge.

Dale, A. M. (1969) The Collected Papers, Cambridge.

Esteban Santos, A. (1998) "Composición axial en Eurpipdies en torno a la mujer y la muerte" en García Novo, E. Y Rodríguez Alfageme, I. (eds.) Dramaturgia y puesta en escena en el teatro griego, Madrid: 99-120.

21 Según N. T. Croally, Euripidean Polemic, Cambridge, Cambridge University Press, 1994, 191 la tragedia se interesó en la manera como las posiciones en el espacio determinan el estatus o identidad y cómo la definición del espacio de la polis fue crucial para la ideología ateniense. Eurípides trazó el espacio no sólo como marco en el cual la ideología puede ser examinada, sino que el espacio mismo está sostenido para ser examinado, como en Medea. 
Furley, W. D. (2000) "Hymns in Euripidean Tragedy", en Cropp. M., Lee, K y D. Sansone, Euripides and Tragic Theatre in the Late Fifth Century, Illinois.

Goldhill, S. (1990) "The Great Dionysia and Civic ideology" en Winkler, J and Zeitlin, F. (eds) Nothing to do with Dionysos? , Princeton: 97-129.

González de Tobia, A. M. (1983) "Doble logos en Medea” en Argos 7: 101-112.

Henrichs, A. (199-1995) "Why Should I Dance": Choral Self-Referenciality in Greek Tragedy", Airon 3.1: 56-111.

Kranz, W. (1933) Stasimon, Berlin.

Nagy, G. (1990) Pindar's Homer, Baltimore and London.

NagY, G. (1994-1995) "Transformation of Choral Lyric traditions in the Context of Athenian State Theater", Arion 3.1: 41-55.

PARRY, H. (1978) The Lyric Poems of Greek Tragedy, Toronto and Sarasota.

Race, W. H. (1990) Style and Rhetoric in Pindar' Odes, Atlanta.

Rodríguez Adrados, F. (1976) Orígenes de la lírica griega, Madrid.

Abstract: Aesthetic integration of the chorus in Greek tragedy is a critical task attractive. On several occasions we have stated our position on coral functionality within the production of Euripides' tragedy. Medea's third stasimon provides an adequate corpus to show that fictional representation of theatrical activity, holding the original cult mimesis, provides the mythohistorical poiesis in honor of the contemporary Athens of Euripides.

Keywords: Chorus, stasimon, Euripides, Medea, mythohistorical poíesis. 